\title{
Relationship between vasospasm, cerebral perfusion, and delayed cerebral ischemia after aneurysmal subarachnoid hemorrhage
}

\author{
Jan W. Dankbaar • Mienke Rijsdijk • \\ Irene C. van der Schaaf • Birgitta K. Velthuis • \\ Marieke J. H. Wermer • Gabriel J. E. Rinkel
}

Received: 6 May 2009 / Accepted: 13 July 2009/Published online: 22 July 2009

(C) The Author(s) 2009. This article is published with open access at Springerlink.com

\begin{abstract}
Introduction Vasospasm after aneurysmal subarachnoid hemorrhage (SAH) is thought to cause ischemia. To evaluate the contribution of vasospasm to delayed cerebral ischemia (DCI), we investigated the effect of vasospasm on cerebral perfusion and the relationship of vasospasm with DCI.

Methods We studied 37 consecutive SAH patients with CT angiography (CTA) and CT perfusion (CTP) on admission and within 14 days after admission or at time of clinical deterioration. CTP values (cerebral blood volume, cerebral blood flow $(\mathrm{CBF})$ and mean transit time), degree of vasospasm on CTA, and occurrence of DCI were recorded. Vasospasm was categorized as follows: no spasm $(0-25 \%$ decrease in vessel diameter), moderate spasm $(25-50 \%$ decrease), and severe spasm ( $>50 \%$ decrease). The correspondence of the flow territory of the most spastic vessel with the least perfused region was evaluated, and differences in perfusion values and occurrence of DCI between degrees of vasospasm were calculated with $95 \%$ confidence intervals $(95 \% \mathrm{CI})$.

Results Fourteen patients had no vasospasm, 16 were moderate, and seven were severe. In $65 \%$ of patients with
\end{abstract}

J. W. Dankbaar $(\bowtie) \cdot$ M. Rijsdijk $\cdot$ I. C. van der Schaaf

B. K. Velthuis

Department of Radiology (HP E01.132),

University Medical Center,

P. O. Box 85500, 3508 GA Utrecht, The Netherlands

e-mail: j.w.dankbaar@umcutrecht.nl

M. J. H. Wermer · G. J. E. Rinkel

Department of Neurology,

Rudolf Magnus Institute for Neuroscience,

University Medical Center,

Utrecht, The Netherlands spasm, the flow territory of the most spastic vessel corresponded with the least perfused region. There was significant CBF (milliliters per $100 \mathrm{~g}$ per minute) difference $(-21.3 ; 95 \% \mathrm{CI},-37 \leftrightarrow-5.3)$ between flow territories of severe and no vasospasm. Four of seven patients with severe, six of 16 with moderate, and three of 14 patients with no vasospasm had DCI.

Conclusion Vasospasm decreases cerebral perfusion, but corresponds with the least perfused region in only two thirds of our patients. Furthermore, almost half of patients with severe vasospasm do not have DCI. Thus, although severe vasospasm can decrease perfusion, it may not result in DCI.

Keywords Subarachnoid hemorrhage - Vasospasm · Delayed cerebral ischemia $\cdot$ CT perfusion

\section{Introduction}

Delayed cerebral ischemia (DCI) is a serious complication of aneurysmal subarachnoid hemorrhage (SAH). It typically occurs 4-12 days after initial bleeding and increases the risk of poor outcome in patients that survive the first days [1]. The onset of DCI is characterized by a decrease in consciousness, new focal deficit, or both. Presence or absence of angiographic vasospasm (luminal narrowing) is often used as a criterion for DCI. TCD measurements of flow velocities in the large cerebral vessels are performed daily in many hospitals, and SAH patients with neurological symptoms frequently undergo angiography to detect vasospasm. Furthermore, many strategies to treat DCI, such as induced hypertension and hypervolemia or balloon angioplasty, are developed with the conviction that vaso- 
spasm is the main cause of deterioration and ischemia [2-4]. However, vasospasm does not necessarily lead to cerebral infarcts (positive predictive value around 70\%) [5], and cerebral infarcts after SAH have been reported to occur in the absence of vasospasm [6]. In the development of DCI, infarction is preceded by a decreased cerebral perfusion $[7,8]$. It would therefore make sense to measure perfusion in an area that is fed by a spastic vessel to evaluate the contribution of vasospasm to DCI.

CT perfusion imaging (CTP) is an accurate tool to measure cerebral perfusion [9]. Within the same imaging study, CTP can be combined with CT angiography (CTA), which can be used to accurately detect vasospasm $[10,11]$. The combination of CTA and CTP makes it possible to study the relationship between vasospasm and perfusion deficits.

The purpose of this study was to investigate the effects of vasospasm (measured with CTA) on cerebral perfusion (measured with CTP) and its relation with DCI.

\section{Clinical materials and methods}

\section{Patients}

All patients admitted to our hospital with SAH, proven on non-contrast CT (NCCT) or CSF analysis, were prospectively enrolled. We included all patients who were admitted within $72 \mathrm{~h}$ after SAH with written informed consent. Included patients were scanned on admission and at time of clinical deterioration or within 14 days after admission if no deterioration occurred. Exclusion criteria for the present study were (1) patients with a cause of SAH other than a ruptured aneurysm and (2) patients younger than 18 years of age. For all patients, the clinical status on admission (according to the World Federation of Neurological Surgeons (WFNS) scale) [12] and time to follow-up was recorded. Informed consent for the study was obtained from all patients, and the study was approved by the ethics committee of our institution. All patients were treated according to a standardized protocol that consisted of absolute bed rest until aneurysm treatment, oral administration of nimodipine, cessation of antihypertensive medication, and intravenous administration of fluid aiming for normovolemia.

\section{Imaging technique}

In our hospital, all patients with SAH routinely undergo a CTA on admission to evaluate the presence and configuration of aneurysms. At the time of clinical deterioration or about 1 week after admission in clinically stable patients, included patients underwent a NCCT, CTP, and CTA scan (follow-up scan). The CTP scan was performed prior to CTA and replaces the timing scan for the CTA. CTA can be used for detection of vasospasm with an accuracy equal to that of the gold-standard DSA [10, 11]. CTP imaging measures cerebral perfusion on tissue level and provides accurate and reliable data compared to the gold standard xenon CT [9]. СTP gives information on cerebral blood volume (CBV), cerebral blood flow (CBF), mean transit time (MTT), and time to peak (TTP).

All imaging studies were executed on a 16-slice spiral CT scanner (Philips Mx8000 LDT, Best, the Netherlands). CTP source data were derived from sequential scans covering a slab of $2.4 \mathrm{~cm}$ thickness selected $3 \mathrm{~cm}$ above the sella turcica and angulated parallel to the meato-orbital line to contain the upper parts of the lateral ventricles and the basal ganglia. For the CTP scan, $40 \mathrm{ml}$ of nonionic contrast agent (Iopromide, Ultravist, $300 \mathrm{mg}$ iodine $/ \mathrm{ml}$, Schering, Berlin, Germany) was injected into the cubital vein (18-gauge needle) at a rate of $5 \mathrm{ml} / \mathrm{s}$ followed by a $40 \mathrm{ml}$ saline flush at a rate of $5 \mathrm{ml} / \mathrm{s}$ using a dual-power injector (Stellant Dual CT injector, Medrad Europe BV, Beek, the Netherlands). The following parameters were used: $90 \mathrm{kVp}, 150 \mathrm{mAs}, 8 \times 3 \mathrm{~mm}$ collimation, $512 \times 512$ matrix, $200 \mathrm{~mm}$ field of view (FOV), 1 image per $2 \mathrm{~s}$ during $60 \mathrm{~s}$ (total 30 images), and UB filter and standard resolution.

For the CTA scan, $70 \mathrm{ml}$ of nonionic contrast agent was injected into the cubital vein, $50 \mathrm{ml}$ at a rate of $5 \mathrm{ml} / \mathrm{s}$, $20 \mathrm{ml}$ at a rate of $4 \mathrm{ml} / \mathrm{s}$, and followed by a $40 \mathrm{ml}$ saline flush at a rate of $4 \mathrm{ml} / \mathrm{s}$. Scanning was performed with $120 \mathrm{kVp}, 180 \mathrm{mAs}, 16 \times 0.75 \mathrm{~mm}$ collimation, $512 \times 512$ matrix, $160 \mathrm{FOV}$, rotation time of $0.4 \mathrm{~s}$, pitch of 0.9 , slice thickness of $1 \mathrm{~mm}$, reconstruction increment of $0.5 \mathrm{~mm}$, and filter B and UF resolution. All CT angiograms were evaluated on a Philips MXView workstation.

\section{CTA and CTP measurements and data processing}

CTA scans were reconstructed at $10-\mathrm{mm}$ contiguous axial, sagittal, and coronal maximal intensity projection images. The smallest diameters of both the proximal (A1) and distal (A2) segments of the anterior cerebral artery (ACA) and the proximal (M1) and distal (M2) segments of the middle cerebral artery (MCA) were measured by one of two observers blinded for the perfusion results and for the clinical condition of the patient (IvdS, MR) using the best projecting viewing plane.

The degree of vasospasm was assessed by dividing the vessel diameter on the follow-up scan with the vessel diameter measured on the admission scan. We assumed that no vasospasm was present on the admission scan since vasospasm generally occurs more than 3 days after $\mathrm{SAH}$ [1]. Vasospasm was categorized as follows: (1) none, $0 \%$ to 


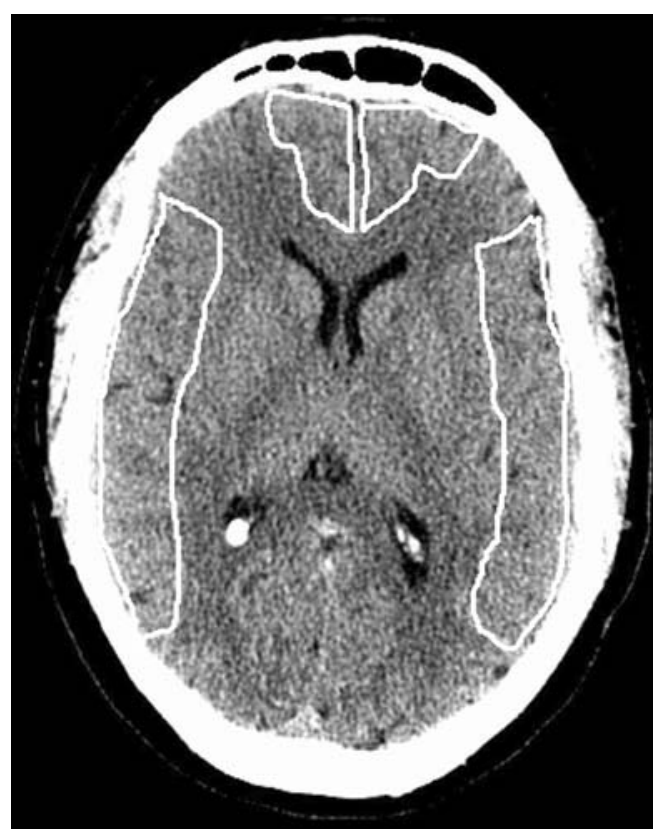

Fig. 1 Regions of interest drawn by hand bilaterally in the cortical gray matter of the flow territories of the anterior and middle cerebral artery at the level of the basal ganglia

$25 \%$ decrease in vessel diameter on the follow-up scan; (2) moderate, $25-50 \%$ decrease; and (3) severe, $>50 \%$ decrease $[13,14]$.

CTP scans were reconstructed at 6-mm contiguous axial images. Data were transferred to a Philips workstation for postprocessing. The CTP algorithm was based upon the central volume principle, and CBF was calculated by the deconvolution method [15]. Perfusion was measured in regions of interest (ROIs) drawn by hand bilaterally in the cortical gray matter of the flow territories of the anterior and middle cerebral artery at the level of the basal ganglia (Fig. 1). The ROIs were drawn by one observer blinded for the clinical condition and CTA images of the patient (MR). The posterior circulation was not included in this study.

\section{DCI}

The occurrence of DCI was assessed by a neurologist (MW) blinded for the CTP and CTA scan results. DCI was defined as a clinical deterioration (new focal deficit, decrease Glasgow Coma Scale, or both) lasting $2 \mathrm{~h}$ or longer with no evidence for rebleeding or hydrocephalus on $\mathrm{CT}$ and no other medical causes such as cardiovascular or pulmonary complications, infections, or metabolic disturbances.

\section{Analysis}

To investigate the effect of vasospasm on cerebral perfusion, we assessed whether the flow territory of the most spastic vessel corresponded with the ROI with lowest perfusion. Additionally, differences in mean perfusion values and their respective $95 \%$ confidence intervals $(95 \% \mathrm{CI})$ were calculated between flow territories of moderate and severe vasospastic vessels and flow territories of vessels without spasm. The category of spasm was based on the most spastic vessel segment (proximal or distal) since flow territories are supplied by the proximal and distal segment, which may both influence cerebral perfusion. Thus, per patient, four vessels (proximal and distal MCA and ACA) with corresponding perfusion were incorporated in the analysis.

To investigate the relationship of vasospasm and DCI, we calculated differences (and their 95\% CIs) in the percentage of patients with DCI between the different degrees of vasospasm (most spastic vessel).

For all analyses, a difference was considered statistically significant if the $95 \%$ CI did not contain zero.

\section{Results}

Forty patients met our inclusion criteria. Three patients were excluded because the follow-up scan could not be evaluated due to motion artifacts or improper timing of contrast bolus injection. The characteristics of the 37 remaining patients and time of follow-up scanning are shown in Table 1.

Of all patients, 14 had no vasospasm, 16 had moderate vasospasm, and seven had severe vasospasm. In 15 of the 23 patients with moderate to severe vasospasm $(65 \%)$, the flow territory of the vessel with most severe vasospasm corresponded with the least perfused region (Fig. 2). With increasing degree of vasospasm, cerebral perfusion in the corresponding flow territory decreased (Table 2). Mean

Table 1 Patient characteristics.

\begin{tabular}{ll}
\hline & $\begin{array}{l}\text { Number of patients } \\
\text { (total=37) }\end{array}$ \\
\hline Women (\%) & $28(76 \%)$ \\
Mean age in years (range) & 58 (range 32-77) \\
WFNS grade (number of patients) & \\
1 & $15(41 \%)$ \\
2 & $8(22 \%)$ \\
3 & $1(3 \%)$ \\
4 & $6(16 \%)$ \\
5 & $7(19 \%)$ \\
Median days after SAH for follow-up scan & $7($ range $3-12)$ \\
Delayed cerebral ischemia (DCI) & $13(35 \%)$ \\
\hline
\end{tabular}

WFNS grade World Federation of Neurological Surgeons clinical grading scale 
Fig. 2 CTA vasospasm and its effect on cerebral perfusion as seen on CTP color maps: a 43-year-old man, 10 days after SAH with vasospasm (red arrow) in the left middle cerebral artery and an area of low perfusion in the flow territory of this artery (most visible on the MTT map); b 60-year-old woman, 5 days after SAH with vasospasm (red arrow) in all anterior cerebral arteries (ACA; note the presence of an accessory ACA) and no areas of low perfusion in the flow territory of these arteries

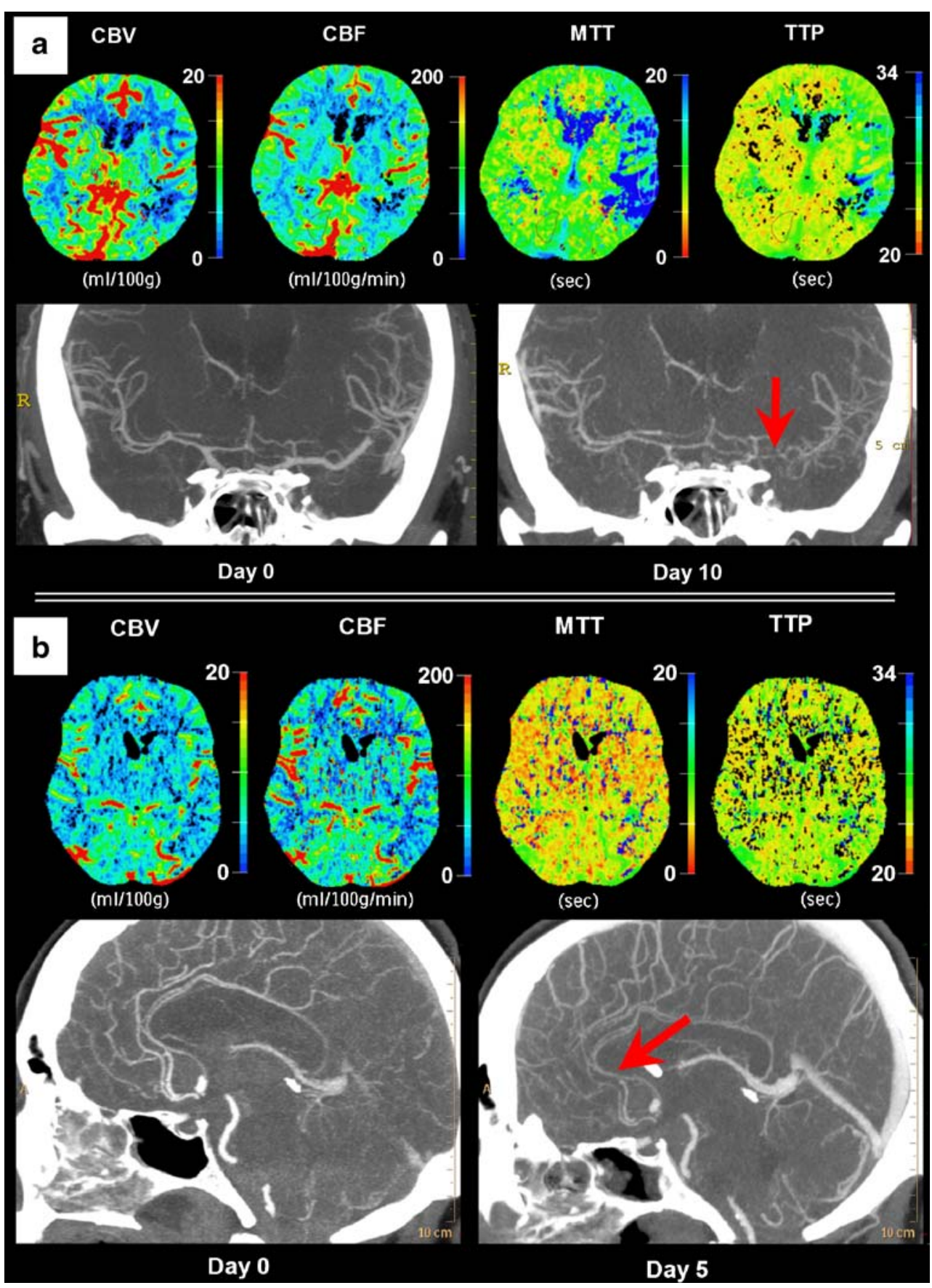

cerebral perfusion values were most favorable (highest CBV and CBF values and lowest MTT and TTP values) in the flow territories supplied by arteries without vasospasm and least favorable in flow territories supplied by arteries with severe vasospasm. Differences in perfusion were more prominent between none and severe vasospasm than between none and moderate vasospasm (Table 2). Differences in $\mathrm{CBF}$ between none and severe vasospasm were statistically significant (Table 2).

Four of seven $(57 \%)$ patients with severe vasospasm and six of $16(38 \%)$ with moderate vasospasm had DCI compared to three of $14(21 \%)$ of patients with no vasospasm. The difference in percentage DCI between no vasospasm and moderate vasospasm was $17 \%(95 \% \mathrm{CI},-15 \leftrightarrow 49)$ and between no and severe $36 \%$ (95\% CI, $0 \leftrightarrow 68 \%$ ).

\section{Discussion}

Our results show that cerebral perfusion decreases with increasing degree of vasospasm. Our results also show that patients with severe vasospasm more often experience DCI 
Table 2 Mean cerebral perfusion values in the flow territories of vessels with no, moderate, and severe vasospasm.

\section{Vasospasm}

None $(<25 \%)$

$N=14$
Moderate
$(25-50 \%), N=16$
Difference between moderate and none (95\% CI)

$$
\begin{aligned}
& \text { Severe }(>50 \%) \\
& N=7
\end{aligned}
$$

8

Number of flow territories ${ }^{\mathrm{a}}$

Mean CBV (ml/100 g)

Mean CBF (ml/100 g/min)

94

Mean MTT (s)

Mean TTP (s)

4.3

59.5

4.8

22.8

$C B V$ cerebral blood volume, $C B F$ cerebral blood flow, MTT mean transit time, TTP time to peak

${ }^{\text {a }}$ Thirty-seven patients with four flow territories=total of 148 flow territories

${ }^{\mathrm{b}}$ Statistically significant

than patients without vasospasm. However, almost half of the patients with severe vasospasm do not experience DCI. This suggests that although vasospasm causes a decrease in perfusion in the area behind the spasm, severe vasospasm alone is not sufficient to cause DCI. Most likely, other factors play a role in decreasing cerebral perfusion to a level where DCI does occur.

We studied a relatively large consecutive series of symptomatic and asymptomatic $\mathrm{SAH}$ patients to evaluate the effect of vasospasm on cerebral perfusion. In the setting of vasospasm, cerebral perfusion has previously been investigated, but rarely were asymptomatic patients included. Our findings that vasospasm affects cerebral perfusion to an increasing extent with increasing vasospasm are in accordance with the results of other clinical and experimental studies [13, 16-19]. Differences in quantitative perfusion values between severe and moderate to absent vasospasm were comparable to other studies quantifying perfusion in angiographic vasospasm [18, 19]. A recent study showed that qualitative assessment of CTP color maps correlates well with vasospasm on DSA. However, this study also showed that in $70 \%$ of cases, no vasospasm is present on DSA although the patients experienced neurological symptoms at that time [20]. In other studies, $11-49 \%$ of patients without vasospasm experienced neurological symptoms suspective of DCI [16, 17, 19]. However, these studies did not look at asymptomatic patients. In a study where patients with and without symptoms of DCI were examined, $36 \%$ of patients had severe vasospasm (compared to $19 \%$ in our study), while $49 \%$ of all patients had DCI (compared to $35 \%$ in our study) [18]. A correlation between the two was not given. Our results show that although severe vasospasm decreases cerebral perfusion, it does not cause DCI in almost half of our patients. This suggests that the decrease in perfusion caused by vasospasm is not sufficient to cause
DCI in all patients, and the presence of vasospasm is not equivalent to DCI.

DCI is likely to be a focal problem [21, 22] that is caused by a decrease in cerebral perfusion resulting in ischemia or infarction. Cerebral perfusion measurements reflect the net effect of all factors that contribute to the development of DCI. Failing compensatory mechanisms in the presence of vasospasm together with other pathogenic processes play a role. Firstly, cerebral autoregulation is often disturbed in SAH patients [23, 24]. With disturbed autoregulation, distal resistance vessels cannot compensate sufficiently to maintain adequate $\mathrm{CBF}$ in a setting of vasospasm or other hemodynamic challenges [13, 23, 25]. Secondly, blood flow through collateral circulation can compensate for the drop in CBF in flow territories behind a spastic vessel segment [26]. Absence of collateral flow consequently results in less compensation. Thirdly, there are other pathogenetic processes not visible on CTA that can contribute to a decrease of $\mathrm{CBF}$ and the development of DCI. These processes include small-artery spasm and platelet aggregation [6, 22, 27-29]. All these factors can explain the discrepancy between the presence of vasospasm and presence of DCI and also that the flow territory of the vessel with most severe vasospasm corresponds with the least perfused region in less than two thirds of our patients.

We acknowledge that the used imaging technique has some limitations.

Brain perfusion measurements with CTP are limited by its coverage (in this study only $2.4 \mathrm{~cm}$ ). However, with increasing detectors, this scan volume will expand. Also, CTP data of the posterior fossa can rarely be used and were excluded in this study since large veins in the posterior fossa influence CTP measurements due to partial volume effects. 
Another limitation may be that we did not vary the region of perfusion measurements with the location of the spasm (distal or proximal in the feeding vessel). A small area of decreased perfusion due to distal spasm may therefore have been averaged with the larger region of normal perfusion. However, by not using information on spasm for the CTP assessment, we reduced observer bias.

The strength of this study lies in the fact that a relatively large consecutive series of symptomatic and asymptomatic SAH patients was prospectively collected. A good comparison could thus be made between patients with different degrees of vasospasm with and without DCI.

\section{Conclusions}

Our findings emphasize that although cerebral vasospasm does affect cerebral perfusion, it is by itself not sufficient to cause DCI. This reflects the multifactorial origin of DCI and affirms the poor diagnostic value of vasospasm for DCI. The net effect on perfusion of mechanisms compensating for vasospasm and additional pathogenetic processes can be measured with CTP. Cerebral perfusion should therefore be more thoroughly evaluated as a diagnostic tool in the acute phase of DCI, and angiographic vasospasm on CTA may not be the proper gold standard for diagnosing DCI.

Conflict of interest statement We declare that we have no conflict of interest.

Open Access This article is distributed under the terms of the Creative Commons Attribution Noncommercial License which permits any noncommercial use, distribution, and reproduction in any medium, provided the original author(s) and source are credited.

\section{References}

1. van Gijn J, Kerr RS, Rinkel GJ (2007) Subarachnoid haemorrhage. Lancet 369:306-318

2. Myburgh JA (2005) "Triple h" therapy for aneurysmal subarachnoid haemorrhage: real therapy or chasing numbers? Crit Care Resusc 7:206-212

3. Qureshi AI, Suarez JI, Bhardwaj A, Yahia AM, Tamargo RJ, Ulatowski JA (2000) Early predictors of outcome in patients receiving hypervolemic and hypertensive therapy for symptomatic vasospasm after subarachnoid hemorrhage. Crit Care Med 28:824-829

4. Weyer GW, Nolan CP, Macdonald RL (2006) Evidence-based cerebral vasospasm management. Neurosurg Focus 21:E8

5. Rabinstein AA, Friedman JA, Weigand SD, McClelland RL, Fulgham JR, Manno EM, Atkinson JL, Wijdicks EF (2004) Predictors of cerebral infarction in aneurysmal subarachnoid hemorrhage. Stroke 35:1862-1866

6. Stein SC, Levine JM, Nagpal S, LeRoux PD (2006) Vasospasm as the sole cause of cerebral ischemia: how strong is the evidence? Neurosurg Focus 21:E2
7. Harrod CG, Bendok BR, Batjer HH (2005) Prediction of cerebral vasospasm in patients presenting with aneurysmal subarachnoid hemorrhage: a review. Neurosurgery 56:633-654

8. Pham M, Johnson A, Bartsch AJ, Lindner C, Mullges W, Roosen K, Solymosi L, Bendszus M (2007) Ct perfusion predicts secondary cerebral infarction after aneurysmal subarachnoid hemorrhage. Neurology 69:762-765

9. Wintermark M, Thiran JP, Maeder P, Schnyder P, Meuli R (2001) Simultaneous measurement of regional cerebral blood flow by perfusion ct and stable xenon CT: a validation study. AJNR Am J Neuroradiol 22:905-914

10. Chaudhary SR, Ko N, Dillon WP, Yu MB, Liu S, Criqui GI, Higashida RT, Smith WS, Wintermark M (2008) Prospective evaluation of multidetector-row ct angiography for the diagnosis of vasospasm following subarachnoid hemorrhage: a comparison with digital subtraction angiography. Cerebrovasc Dis 25:144-150

11. Yoon DY, Choi CS, Kim KH, Cho BM (2006) Multidetector-row ct angiography of cerebral vasospasm after aneurysmal subarachnoid hemorrhage: comparison of volume-rendered images and digital subtraction angiography. AJNR Am J Neuroradiol 27:370-377

12. [No authors listed] (1988) Report of world federation of neurological surgeons committee on a universal subarachnoid hemorrhage grading scale. J Neurosurg 68:985-986

13. Lodi CA, Ursino M (1999) Hemodynamic effect of cerebral vasospasm in humans: a modeling study. Ann Biomed Eng 27:257-273

14. Voldby B, Enevoldsen EM, Jensen FT (1985) Regional CBF, intraventricular pressure, and cerebral metabolism in patients with ruptured intracranial aneurysms. J Neurosurg 62:48-58

15. Axel L (1983) Tissue mean transit time from dynamic computed tomography by a simple deconvolution technique. Invest Radiol 18:94-99

16. Aralasmak A, Akyuz M, Ozkaynak C, Sindel T, Tuncer R (2009) $\mathrm{Ct}$ angiography and perfusion imaging in patients with subarachnoid hemorrhage: correlation of vasospasm to perfusion abnormality. Neuroradiology 51:85-93

17. Binaghi S, Colleoni ML, Maeder P, Uske A, Regli L, Dehdashti AR, Schnyder P, Meuli R (2007) Ct angiography and perfusion ct in cerebral vasospasm after subarachnoid hemorrhage. AJNR Am J Neuroradiol 28:750-758

18. Sviri GE, Britz GW, Lewis DH, Newell DW, Zaaroor M, Cohen W (2006) Dynamic perfusion computed tomography in the diagnosis of cerebral vasospasm. Neurosurgery 59:319-325

19. Wintermark M, Ko NU, Smith WS, Liu S, Higashida RT, Dillon WP (2006) Vasospasm after subarachnoid hemorrhage: utility of perfusion ct and ct angiography on diagnosis and management. AJNR Am J Neuroradiol 27:26-34

20. Wintermark M, Dillon WP, Smith WS, Lau BC, Chaudhary S, Liu S, Yu M, Fitch M, Chien JD, Higashida RT, Ko NU (2008) Visual grading system for vasospasm based on perfusion ct imaging: comparisons with conventional angiography and quantitative perfusion ct. Cerebrovasc Dis 26:163-170

21. Rijsdijk M, van der Schaaf IC, Velthuis BK, Wermer MJ, Rinkel GJ (2008) Global and focal cerebral perfusion after aneurysmal subarachnoid hemorrhage in relation with delayed cerebral ischemia. Neuroradiology 50:813-820

22. Weidauer S, Vatter H, Beck J, Raabe A, Lanfermann H, Seifert V, Zanella F (2008) Focal laminar cortical infarcts following aneurysmal subarachnoid haemorrhage. Neuroradiology 50:1-8

23. Jaeger M, Schuhmann MU, Soehle M, Nagel C, Meixensberger J (2007) Continuous monitoring of cerebrovascular autoregulation after subarachnoid hemorrhage by brain tissue oxygen pressure reactivity and its relation to delayed cerebral infarction. Stroke 38:981-986

24. Hattingen E, Blasel S, Dettmann E, Vatter H, Pilatus U, Seifert V, Zanella FE, Weidauer S (2008) Perfusion-weighted MRI to 
evaluate cerebral autoregulation in aneurysmal subarachnoid haemorrhage. Neuroradiology 50:929-938

25. Pucher RK, Auer LM (1988) Effects of vasospasm in the middle cerebral artery territory on flow velocity and volume flow. A computer simulation. Acta Neurochir (Wien) 93:123-128

26. Weidauer S, Lanfermann H, Raabe A, Zanella F, Seifert V, Beck J (2007) Impairment of cerebral perfusion and infarct patterns attributable to vasospasm after aneurysmal subarachnoid hemorrhage: a prospective MRI and DSA study. Stroke 38:1831-1836
27. Kozniewska E, Michalik R, Rafalowska J, Gadamski R, Walski M, Frontczak-Baniewicz M, Piotrowski P, Czernicki Z (2006) Mechanisms of vascular dysfunction after subarachnoid hemorrhage. J Physiol Pharmacol 57(Suppl 11):145-160

28. Ng WH, Moochhala S, Yeo TT, Ong PL, Ng PY (2001) Nitric oxide and subarachnoid hemorrhage: elevated level in cerebrospinal fluid and their implications. Neurosurgery 49:622-626 discussion 626-627

29. Romano JG, Rabinstein AA, Arheart KL, Nathan S, CampoBustillo I, Koch S, Forteza AM (2008) Microemboli in aneurysmal subarachnoid hemorrhage. J Neuroimaging 18:396-401 